\title{
Systematic review on the prevalence of lack of capacity in medical and psychiatric settings
}

\author{
Authors: Peter Lepping, ${ }^{A}$ Thushara Stanly ${ }^{B}$ and Jim Turner ${ }^{C}$
}

\begin{abstract}
Recent court cases in England and Wales have refocused attention on patients' decision-making capacity to consent. Little is known about the prevalence of incapacity across specialities but decision-making capacity is likely to be overestimated by clinicians. The aim of this systematic review is to estimate the prevalence of incapacity to consent to treatment or admission in different medical and psychiatric settings, and compare the two. We conducted an electronic search following PRISMA principles and included 35 studies in psychiatric and 23 studies in medical settings. The 58 included studies revealed 70 data sets across all settings. For psychiatric settings the weighted average proportion of patients with incapacity was $45 \%$ (95\% confidence interval (CI) $39-51 \%$ ). For medical settings, the weighted average proportion of patients with incapacity was $34 \%$ (95\% CI $25-44 \%$ ). The two groups are not significantly different from each other in terms of the proportion of incapacity $(p=0.92)$. A considerable number of medical and psychiatric patients lack capacity to make treatment and assessment decisions. Clinicians should be more alert to the possibility that their patients may lack decision-making capacity. Assessment of capacity should be frequent using the appropriate legal frameworks to act in the best interest of patients.
\end{abstract}

KEYWORDS: Capacity, incapacity, medicine, psychiatry, prevalence

\section{Introduction}

Decision-making capacity is the basis for medical decision making. Many countries have introduced legislation to regulate decision making for people who lack capacity; in England and Wales this is the Mental Capacity Act (MCA), 2005. ${ }^{1}$ However, there is little guidance to aid clinicians to estimate the expected prevalence of incapacity on their wards. Previous studies suggested that a mini mental state examination score below

Authors: A consultant psychiatrist and honorary professor, Betsi Cadwaladr University Local Health Board, and Centre for Mental Health and Society, Wrexham, UK, and Mysore Medical College and Research Institute, Mysore, India; ${ }^{B}$ specialist registrar in psychiatry, Betsi Cadwaladr University Local Health Board, Wrexham, UK;

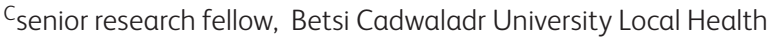
Board and Bangor University, UK
20 vastly increases the likelihood of incapacity. ${ }^{2}$ A variety of validated tools exist to aid the assessment of decision-making capacity such as the MacArthur Competence Assessment Tool for Treatment (MacCAT-T). Clinicians often overestimate their patient's decision-making capacity. ${ }^{2,3}$ Raymont et al investigated the prevalence of mental incapacity in a cross-sectional study in London and found that incapacity was rarely detected by clinicians or relatives. While the authors noted there was little conflict between patients and treating physicians with regard to treatment decisions, it still leaves the possibility of patients making decisions they do not have the capacity to make. There is a potential for clinical harm, as well as the violation of autonomous choices, if protective measures are not in place because a patient is wrongly assumed to have decision-making capacity.

No review so far has compared prevalence of incapacity in two or more different settings. The aim of our review is to estimate the prevalence of incapacity to consent to treatment or admission in different settings. We have included medical and psychiatric patients covering inpatient, outpatient and other settings as well as subspecialities within psychiatry. The results provide guidance to the level of incapacity that clinicians should expect in a variety of different settings. We also compared medical and psychiatric settings to see whether there is a significant difference.

\section{Methods}

We followed PRISMA principles for systematic reviews. We searched all articles published until November 2013 in Embase, Medline or Psychinfo. We used the following search terms: mental competency/or capacity assessments or decision making/informed consent/or consent to treatment in medical wards or hospital units/inpatients or inpatients hospitals, psychiatric/or schizophrenia/or depressive disorder/or mental disorders/or psychiatric patients substance-related disorders/or mood disorders.

Inclusion criteria:

> participants: any medical or psychiatric patients

$>$ assessment: conducted with a validated tool

$>$ data about the prevalence of incapacity were either stated directly or were possible to calculate from the available data

> data were presented in a binary way (either patients had capacity or not)

$>$ any setting including mixed settings

$>$ reporting: published in peer review journals and available as electronic or paper full text in any language. 


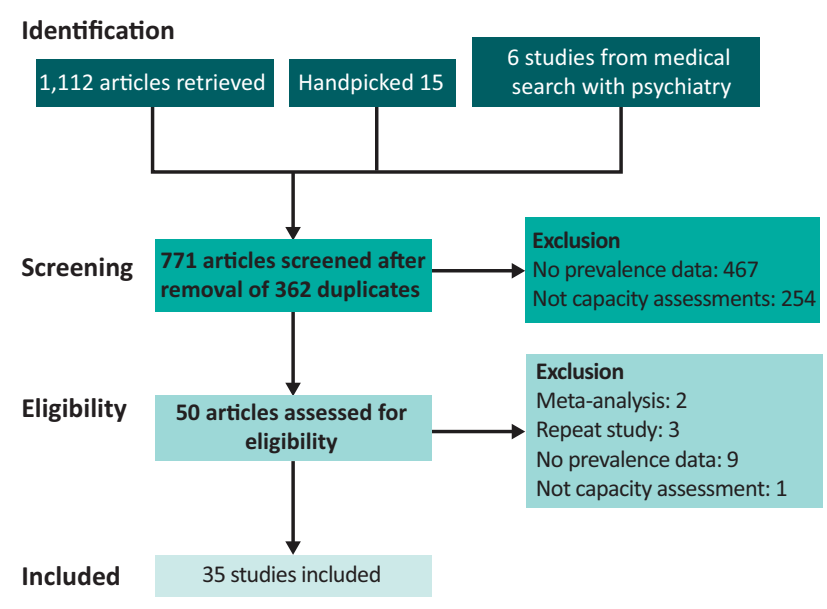

Fig 1. PRISMA flow chart 1 - psychiatry group.

Exclusion criteria:

$>$ no validated tool was used to assess capacity

$>$ prevalence data were not available or possible to calculate

$>$ data were given in a non-binary form

$>$ no sample size was given.

Abstracts were cross-checked and full text articles were independently screened by two authors. Any differences were discussed and settled. We calculated average percentage prevalence of incapacity for various subsettings separating medical and psychiatric settings. We calculated the statistical differences between medical and psychiatric settings. We made the reasonable assumption that due to the large number of studies heterogeneity could be significant, so initial analysis used the random effects model.

\section{Search results}

The search revealed 1,112 and 134 abstracts in psychiatry and medicine respectively (see PRISMA flow charts, Figs 1 and 2).

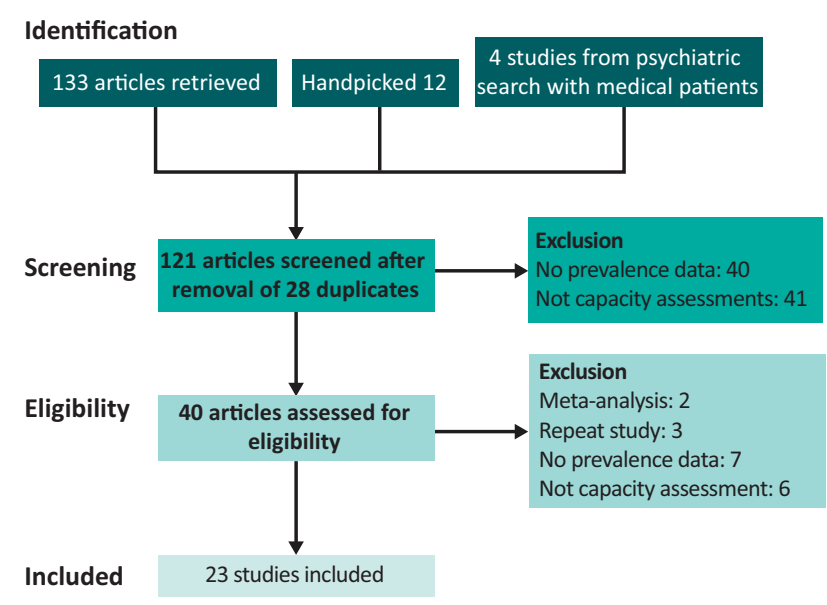

Fig 2. PRISMA flow chart 2 - medicine group.
We included 35 studies in psychiatric (references 5-39) and 23 studies in medical settings (references 4,13,19,29,34,4057). The 58 included studies revealed 70 data sets across settings (inpatient, outpatient, forensic etc). Four data sets were excluded because their results showed $0 \%$ incapacity. Two studies are included where incapacity was $100 \%$; whether this was correct or a typographical error cannot be verified. Confidence intervals (CI) refer to $95 \%$ confidence. Figs 3 and 4 show the forest plots for medical and psychiatric studies separately. Table S1 summarises the included studies.

\section{Results \\ Estimates of prevalence and heterogeneity}

A common solution to analysis where the dependent variable is a proportion is to use a logit transform. The inverse variation weighted prevalence for decision-making capacity for all included studies was $41 \%$ (95\% CI 35.6-46.2\%). Heterogeneity was significant (Cochran Q 601; degrees of freedom (df) 69; $\mathrm{p}<0.001$ ). Differences between all studies were large, therefore requiring a random effects model. The inconsistency value shows the amount of variation between studies due to heterogeneity was $89 \%$ (95\% CI 86-91\%). The test for subgroup differences was not significant (Cochran Q 0.66; df 1; $\mathrm{p}=0.42)$.

For psychiatric settings, the inverse variance weighted proportion of patients with incapacity was 45\% (95\% CI 39-51\%). Heterogeneity was significant (Cochran Q 300; df 42; $\mathrm{p}<0.001$ ). Variance between studies was large ( $\mathrm{I}^{2}$ inconsistency $86 \%$ (95\% CI 82-89\%)), meaning the amount of variation between studies due to heterogeneity was $86 \%$.

For medical settings the inverse variance weighted proportion of patients with incapacity was 34\% (95\% CI 25-44\%).

Heterogeneity was significant (Cochran Q 267; df 26; $<<0.001$ ), with inconsistency $\mathrm{I}^{2}$ at $90 \%$ (95\% CI 87-93\%), showing variation between studies due to heterogeneity was $90 \%$.

\section{Comparing medical and psychiatric settings}

Table 1 shows the average percentage results for all subsettings. Psychiatric and medical settings are not significantly different from each other in terms of the proportion of incapacity (Cochran Q 0.66; df 1; p=0.44).

\section{Discussion}

Our results show the average percentage of patients with incapacity on psychiatric wards is $45 \%$. In medical settings the number is slightly lower with $34 \%$. The figures shown above are similar to results from previous reviews, and we found no significant difference between psychiatric and medical settings. However, differences between diagnostic groups within psychiatry have been shown to be significant in previous studies. Patients with psychosis, dementia and mania are much more likely to lack decision-making capacity than those with depression or personality disorder. ${ }^{36,37,58}$ In medicine, our results suggest a large number of patients lack decision-making capacity, with known higher levels of incapacity in those with learning disability, delirium and neurological disease. ${ }^{41,43,49,50}$ 


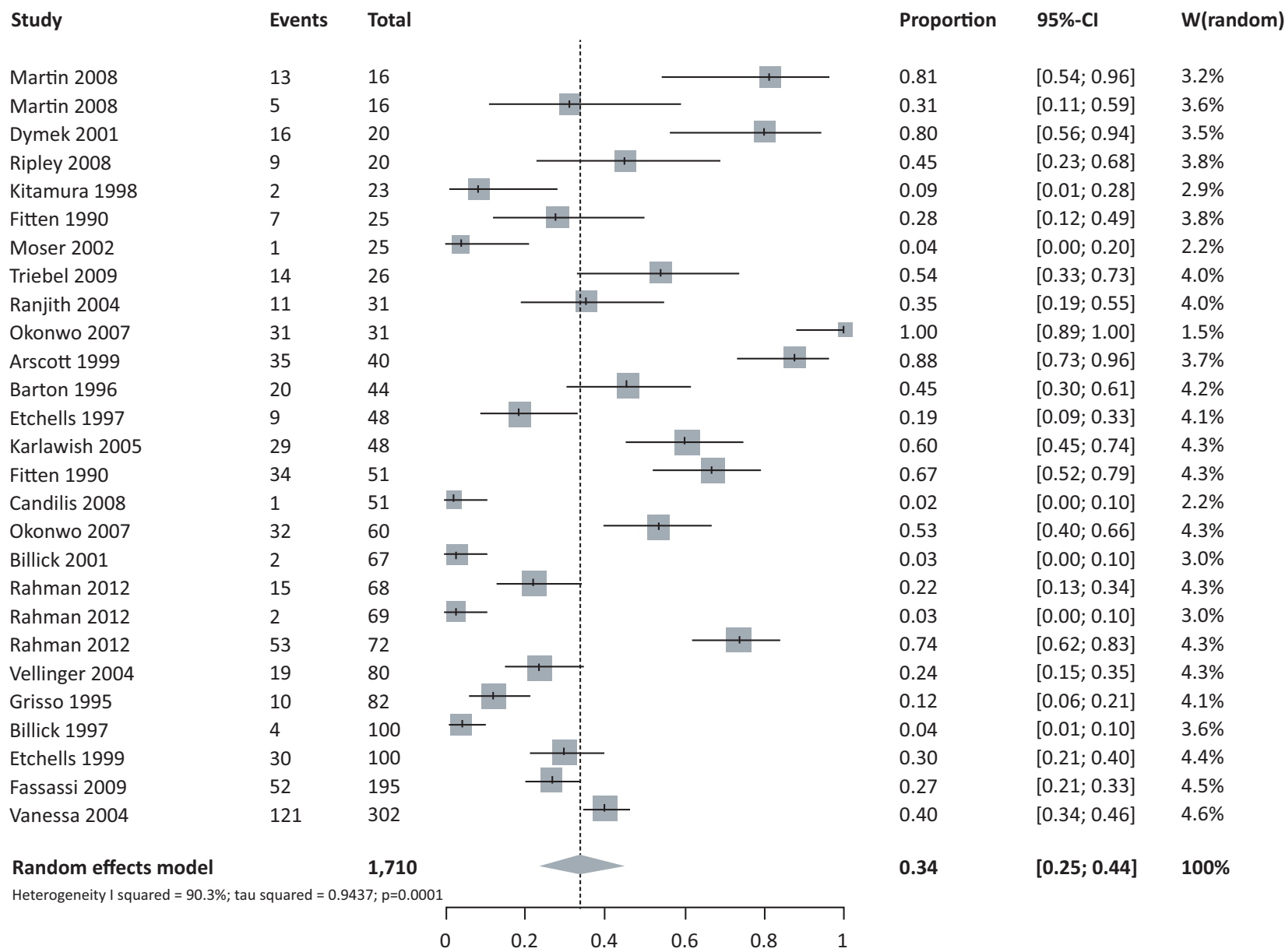

Fig 3. Meta-analysis: random effects model, medical settings. $C I=$ confidence interval.

\section{Comparisons with other studies}

A variety of studies have looked at the prevalence of mental incapacity in medical and psychiatric settings but there have only been two systematic reviews ${ }^{2,59}$ and no review has compared medical and psychiatric percentage prevalence data before. For psychiatric settings, Okai et al ${ }^{59}$ compared a variety of decisions for which decision-making capacity was tested,

\begin{tabular}{lllll} 
Table 1. Results for all subsettings. & & & \\
Group & Setting/patient group & Total data sets, $\mathbf{n}$ & Total patients, $\mathbf{n}$ & $\begin{array}{l}\text { Percentage of incapacity } \\
\text { (weighted average) }\end{array}$ \\
Psychiatry & Inpatients, adult & 25 & 1,597 & 47 \\
Psychiatry & Outpatient, adult/old & 2 & 164 & 58 \\
Psychiatry & IP/OP, adult/old & 5 & 180 & 43 \\
Psychiatry & Old age psychiatry, inpatient & 6 & 277 & 42 \\
Psychiatry & Forensic psychiatry, IP/OP/prison & 4 & 240 & 28 \\
Psychiatry & CAMHS, IP & 1 & 25 & 34 \\
Medical & IP & 13 & 1,022 & 62 \\
Medical & OP & 8 & 336 & 21 \\
Medical & IP/OP & 5 & 285 & 3 \\
Medical & Paediatric OP & 1 & 67 & 28 \\
\hline CAMHS = child and adolescent mental health services; IP=inpatient; OP=outpatient. & &
\end{tabular}


Peter Lepping, Thushara Stanly and Jim Turner

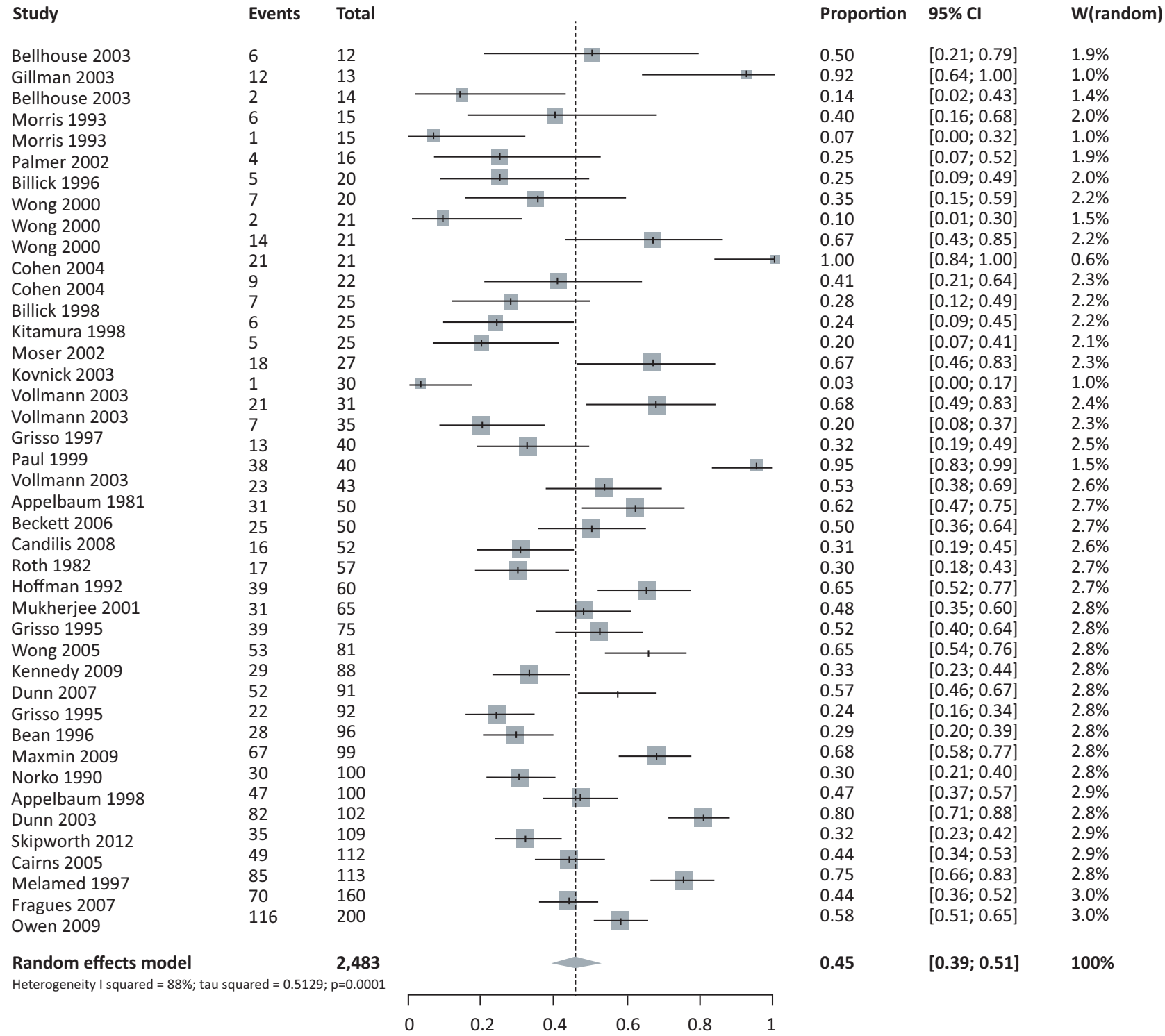

Fig 4. Meta-analysis: random effects mode, psychiatric settings. $C I=$ confidence interval.

but many of these decisions, such as admission or specific treatments, only had a small number of studies included with a wide variety of results.

In the famous CATIE study the authors looked at the longitudinal consent-related abilities among research participants with schizophrenia, and found that $56 \%$ of 1,158 participants had a stable pattern of MacCAT-clinical research (CR) understanding scores, with 24\% deteriorating and 20\% improving over an 18 -month period. ${ }^{60}$ Sessums et al examined the prevalence of incapacity and the accuracy of capacity assessments in adult medical patients. They concluded that $26 \%$ of medical patients lacked capacity compared with $3 \%$ of healthy elderly controls. They added that 'while physicians routinely missed the diagnosis of incapacity (only recognising $42 \%$ of incapable patients), they were usually correct when they made the diagnosis'. Owen et al ${ }^{61}$ found qualitative differences in incapacity between psychiatric and medical patients. They concluded that 'the appreciation ability had more salience to decision-making capacity in a psychiatric setting and the reasoning ability had more salience in the medical setting', thus confirming that the two settings have different priority problems in terms of capacity.

While appreciation of the problem or necessity for treatment is more prominent in psychiatric patients who lack decisionmaking capacity, medical patients primarily struggle with reasoning when they lack decision-making capacity. When we looked at different settings, such as inpatients versus outpatients in various types of psychiatric settings, the differences were smaller than we expected and not statistically significant. Similarly, differences between inpatients and outpatients in either medical or psychiatric settings were not statistically significant. 


\section{Considering the legal context}

To put these figures into a current context, the MCA in England and Wales and the Adults with Incapacity (Scotland) Act 2000 for Scotland set out the legislative frameworks for clinicians describing the process of how to deal with incapable patients and how to act in their best interest. For England and Wales, the recent Supreme Court decisions on the linked appeals regarding the cases of $P$ versus Cheshire West and Chester Council and $P$ and $Q$ versus Surrey County Council ${ }^{62}$ have changed the obligation on hospitals and registered care homes to apply for an authorisation under the Deprivation of Liberty Safeguards (DoLS) when a patient who lacks capacity is subject to continuous supervision and control, and not free to leave. These two questions were termed the 'acid test' by Lady Hale in the Supreme Court judgment. ${ }^{63}$ This scenario is common in hospital settings with regard to patients who lack decision-making capacity. In fact, our results show that lack of decision-making capacity should be assumed in at least $17 \%$ of medical patients at any one time, most of whom will be subject to continuous supervision and control because of the institutionalised way in which hospitals operate, and would not be free to leave if they wanted to. A possible consequence is a sharp increase in DoLS applications, which will have significant resource implications as the process is cumbersome. The UK government has already asked the Law Commission to review the DoLS legislation.

\section{Limitations and strengths}

This meta-analysis yielded a high level of heterogeneity between studies. Even though we only included studies with valid measurement tools, it is not clear those tools could always answer questions around law and ethics. In addition, cut-off points for various tools are still being investigated. The high level of heterogeneity between studies is an important limiting factor that requires a cautious interpretation of our results. In studies about incapacity in different settings, some heterogeneity is expected because of the nature of the research topic. There is also a risk of sampling bias in the available data because of the settings chosen. However, we included more participants than any previous review of this kind, which is its main strength. For the first time, we have directly compared psychiatric with medical patients and attempted to cluster results by subsettings. However, particular caution is necessary when interpreting the results about subsettings because of the often highly selective nature of the patient populations in those settings (for example dementia patients in outpatient settings). In addition, we did not weight the studies according to their quality. We included two subgroup samples with results such as $100 \%$ decision-making incapacity. These studies did, however, not contribute much to the overall result because of their very small sample sizes.

\section{Conclusions and practical implications}

We have examined decision-making capacity across different types of treatment decisions using different, but validated measures of decision-making incapacity. We did not find any difference between medical and psychiatric populations in the frequency of decision-making incapacity when variously measured. The results of this review should serve as a pertinent reminder to clinicians to consider carefully how much capacity an individual patient has. While the legislative frameworks assert an assumption of capacity, in reality, clinicians often assume capacity where it may be lacking. The consequences of this are less frequent and less rigorous discussions about the best interests or potential detriment to the patient. More caution and more frequent capacity assessments are needed to rectify this situation.

\section{Acknowledgements}

The authors thank the staff of the John Spalding library in Wrexham Maelor Hospital for their help with our search.

\section{References}

1 Department of Constitutional Affairs. Mental Capacity Act 2005. Code of Practice. Norwich: The Stationery Office, 2007.

2 Sessums LL, Zembrzuska H, Jackson J L. Does this patient have medical decision-making capacity? JAMA 2011;306:420-7.

3 Lepping P, Ravneesh BN. Overvaluing autonomous decision making. Br J Psychiatry 2014;204:1-2.

4 Raymont V, Bingley W, Buchanan A et al. Prevalence of mental capacity in medical inpatients and associated risk factors-cross sectional study. Lancet 2004;364:1421-7.

5 Appelbaum PS, Mirkin SA, Bateman AL. Empirical assessment of competency to consent to psychiatric hospitalization. Am J Psychiatry 1981;138:1170-6.

6 Appelbaum BC, Appelbaum PS, Grisso T. Competence to consent to voluntary psychiatric hospitalization: a test of a standard proposed by American Psychiatric Association. Psychiatr Serv 1998;49:1193.

7 Palmer BW, Nayak GV, Dunn LB et al. Treatment related decision making capacity in middle aged and older patients with psychosis. Am J Geriatr Psychiatry 2002;10:207-11.

8 Bellhouse J, Holland AJ, Clare ICH. Capacity-based mental health legislation and its impact on clinical practice: 2)treatment in hospital. J Ment Health Law 2003;b:24-36.

9 Cohen BJ, McGarvey EL, Pinkerton RC, Kryzhanivska L. Willingness and competence of depressed and schizophrenic inpatients to consent to research. J Am Acad Psychiatry Law 2004;32:134-43.

10 Beckett J, Chaplin R. Capacity to consent to treatment in patients with acute mania. Psychiatr Bull 2006;30:419-22.

11 Billick SB, Naylor PW, Majeske MF. A clinical study of competency in psychiatric inpatients. Bull Am Acad Psychiatry Law 1996;24: 505-11.

12 Fraguas D, García-Solano F, Chapela E et al. Do psychiatric patients improve their competency to consent to hospitalisation after admission? A prospective study in an acute inpatient ward. Gen Hosp Psychiatry 2007;29:54-62.

13 Moser DJ, Schultz SK, Arndt S et al. Capacity to provide informed consent for participation in Schizophrenia and HIV research. Am J Psychiatry 2002;159:1201-7.

14 Moser DJ, Arndt S, Kanz JE et al. Coercion and informed consent in research involving prisoners. Compr Psychiatry 2004;45:1-9.

15 Owen GS, Szmukler G, Richardson G et al. Mental capacity and psychiatry in-patients -Implications for the new mental health law in England and Wales. Br J Psychiatry 2009;195:257-63.

16 Bean G, Nishisato S, Rector NA, Glancy G. The assessment of competence to make a treatment decision: an empirical approach. Can J Psychiatry 1996;41:85-92.

17 Hoffman BF, Srinivasan J. A study of competence to consent to treatment in a psychiatric hospital. Can J Psychiatry 1992;37:179-82. 
18 Skipworth JJ, Dawson J, Ellis PM. Capacity of forensic patients to consent to treatment. Aust N Z J Psychiatry 2012;47:443-50.

19 Kitamura F, Tomoda A, Tsukada K. Method for assessment of competency to consent in the mentally ill: rationale, development, and comparison with the medically ill. Int J Law Psychiatry 1998;21:223-44.

20 Maxmin K, Cooper C, Potter L, Livingston G. Mental capacity to consent to treatment and admission decision in older adult psychiatric inpatients. Int J Geriatr Psychiatry 2009;24:1367-75.

21 Kovnick JA, Appelbaum PS, Hoge SK, Leadbetter RA. Competence to consent to research among long-stay in patients with chronic schizophrenia. Psychiatric Services 2003;54:1247-52.

22 Dunn LB, Jeste DV. Problem areas in the understanding of informed consent for research: study of middle aged and older patients with psychotic disorders. Psychopharmacology 2002;171:81-5.

23 Dunn LB, Palmer BW, Appelbaum PS et al. Prevalence and correlates of adequate performance on a measure of abilities related to decisional capacity: Differences among three standards for the MacCAT-CR in patients with schizophrenia. Schizophr Res 2007; 89:110-8.

24 Kennedy M, Dornan J, Rutledge E et al. Extra information about treatment is too much for the patient with psychosis. Int J Law Psychiatry 2009;32:369-76.

25 Morris CD, Niederbuhl JM, Mahr JM. Determining the capability of individuals with mental retardation to give informed consent. Am J Ment Retard 1993;98:263-72.

26 Mukherjee S, Shah A. The prevalence and correlates of capacity to consent to a geriatric psychiatry admission. Aging Ment Health 2001;5:335-9.

27 Norko MA, Billick SB, McCarrick RG. A clinical study of competency to consent to voluntary psychiatric hospitalization. Am J Forensic Psychiatry 1990;11:3-15.

28 Paul M, Oyebode F. Competence of voluntary psychiatric patients to give valid consent to neuroleptic medication. Psychiatr Bull 1999;23:463-6.

29 Candilis PJ, Fletcher KE, Geppert CM et al. A direct comparison of research decision-making capacity: schizophrenia/schizoaffective, medically ill, and non-ill subjects. Schizophr Res 2008;99:350-8.

30 Roth LH, Lidz CW, Meisel A. Competency to decide about treatment or research. Int J Law Psychiatry 1982;5:29-50.

31 Gilman RB, Billick SB. Assessing capacity instruments in inpatient legal proceeding. Am J Forensic Psychiatry 2003;24:45-52.

32 Cairns R, Maddock C, Buchanan A et al. Prevalence and predictors of mental incapacity in psychiatry in-patients. Br J Psychiatry 2005; 187:379-85.

33 Billick SB, Edwards JL, Burgert W 3rd et al. A clinical study of competency in child psychiatric inpatients. J Am Acad Psychiatry Law 1998;26:587-94.

34 Grisso T, Appelbaum PS. The Mac Arthur Treatment Competence Study III: Abilities of patients to consent to psychiatric and medical treatment. Law Hum Behav 1995;19:149-74.

35 Grisso T, Appelbaum PS, Hill-Fotouhi C. The MacCAT-T: a clinical tool to assess patient's capacities to make treatment decisions. Psychiatr Serv 1997;48:1415-9.

36 Vollmann J, Bauer A, Danker-Hopfe H. Competence of mentally ill patients: a comparative empirical study. Psychol Med 2003;33: 1463-71.

37 Wong JG, Clare CH, Holland AJ et al. The capacity of people with a mental disability to make a health care decision. Psychol Med 2000;30:295-306

38 Wong JG, Cheung EPT, Chen EYH. Decision-making capacity of inpatients with schizophrenia in Hong Kong. J Nerv Ment Dis 2005;193:316-22.

39 Melamed Y, Kimchi R, Shnit D et al. Insight and competence to consent to psychiatric hospitalization. Med Law 1997;16:721-7.
40 Ranjith G, Hotopf M. 'Refusing treatment - please see' an analysis of capacity assessments carried out by a liaison psychiatry service. J R Soc Med 2004;97:480-2.

41 Arscott K, Dagnan D, Kroese BS. Assessing the ability of people with a learning disability to give informed consent to treatment. Psychol Med 1999;29:1367-75.

42 Barton CD Jr, Mallik HS, Orr WB, Janofsky JS. Clinicians' judgement of capacity of nursing home patients to give informed consent. Psychiatr Serv 1996;47:956-60.

43 Dymek MP, Atchison P, Harrell L, Marson DC. Competency to consent to medical treatment in cognitively impaired patients with Parkinson's disease. Neurology 2001;56:17-24.

44 Etchells E, Katz MR, Shuchman M et al. Accuracy of clinical impressions and mini-mental state exam scores for assessing capacity to consent to major medical treatment. Psychosomatics 1997;38:239-45.

45 Etchells E, Darzins P, Silberfeld M et al. Assessment of patient capacity to consent to treatment. J Gen Intern Med 1999;14:27-34.

46 Fitten LJ, Lusky R, Hamann C. Assessing treatment decisionmaking capacity in elderly nursing home residents. J Am Geriatr Soc 1990;38:1097-104.

47 Fitten LJ, Waite MS. Impact of medical hospitalisation on treatment decision-making capacity in the elderly. Arch Intern Med 1990;150:1717-21.

48 Karlawish JH, Casarett DJ, James BD et al. The ability of persons with Alzheimer disease (AD) to make a decision about taking an AD treatment. Neurology 2005;64:1514-9.

49 Martin RC, Okonkwo OC, Hill J. Medical decision-making capacity in cognitively impaired Parkinson's disease patients without dementia. Mov Disord 2008;23:1867-74.

50 Okonkwo O, Griffith HR, Belue K. Medical decision-making capacity in patients with mild cognitive impairment. Neurology 2007;69:1528-35.

51 Rahman M, Evans KE, Arif N, Gorard DA. Mental capacity in hospitalised patients undergoing percutaneous endoscopic gastrostomy insertion. Clin Nutr 2012;31:224-9.

52 Ripley S, Jones S, Macdonald A. Capacity assessments on medical in-patients referred to social workers for care home placement. Psychiatr Bull 2008;32:56-9.

53 Fassassi S, Bianchi Y, Stiefel F, Waeber G. Assessment of the capacity to consent to treatment in patients admitted to acute medical wards. BMC Med Ethics 2009;10:15.

54 Billick SB, Della Bella P, Burgert W 3rd. Competency to consent to hospitalization in the medical patient. J Am Acad Psychiatry Law 1997;25:191-6.

55 Billick SB, Burgert W 3rd, Friberg G et al. A clinical study of competency to treatment in pediatrics. J Am Acad Psychiatry Law 2001;29:298-302.

56 Triebel KL, Martin RC, Nabors LB, Marson DC. Medical decisionmaking capacity in patients with malignant glioma. Neurology 2009;73:2086-92.

57 Vellinga A, Smit JH, Van Leeuwen E et al. Competence to consent to treatment of geriatric patients: judgements of physicians, family members and the vignette method. Int J Geriatr Psychiatry 2004;19:645-54.

58 Owen GS, Richardson G, David AS et al. Mental capacity to make decisions on treatment in people admitted to psychiatric hospitals: cross-sectional study. BMJ 2008;337:a448.

59 Okai D, Owen G, McGuire $\mathrm{H}$ et al. Mental capacity in psychiatric patients: Systematic review. Br J Psychiatry 2007;191:291-7.

60 Stroup TS, Appelbaum PS, Gu H et al. Longitudinal consent-related abilities among research participants with schizophrenia: results from the CATIE study. Schizophr Res 2011;130:47-52.

61 Owen GS, Szmukler G, Richardson G et al. Decision-making capacity for treatment in psychiatry and medical inpatients: cross sectional, comparative study. Br J Psychiatry 2013;203:461-7. 
62 Royal College of Psychiatrists. Mental Capacity Act - update following $P v$ Cheshire West and $P \& Q v$ Surrey County Council cases. London: Royal College of Psychiatrists, 2014. Available online at www.rcpsych.ac.uk/policyandparliamentary/mentalhealthlaw/mentalcapacityact.aspx [Accessed 18 May 2015].

63 Mental Health law Online. Cheshire West and Chester Council v P (2014) UKSC 19, (2014) MHLO 16. Available online at www. mentalhealthlaw.co.uk/Cheshire_West_and_Chester_Council_ v_P_\%282014\%29_UKSC_19,_\%282014\%29_MHLO_16 [Accessed 18 May 2015].

64 Janofsky JS, McCarthy RJ, Folstein MF. The Hopkins Competency Assessment Test: a brief method for evaluating patients' capacity to give informed consent. Hosp Community Psychiatry 1992;43:132-6.

65 Morris CD, Niederbuhl JM, Mahr JM. Determining the capability of individuals with mental retardation to give informed consent. Am J Ment Retard 1993;98:263-72.

Address for correspondence: Prof P Lepping, Wrexham Academic Unit, Centre for Mental Health and Society, Technology Park, Croesnewydd Road, Wrexham LL13 7TP, UK. Email: peter.lepping@wales.nhs.uk

\section{Assessing trainees in the workplace An e-learning module for secondary care doctors}

Three hours of CPD-approved interactive learning covering:

$>$ feedback

> supervised learning events (SLES)

$>$ workplace-based assessments (WPBAs)

$>$ the role of the Annual Review of Competence Progression (ARCP).

For more information please visit: www.rcplondon.ac.uk/elearning

\section{Royal College} of Physicians

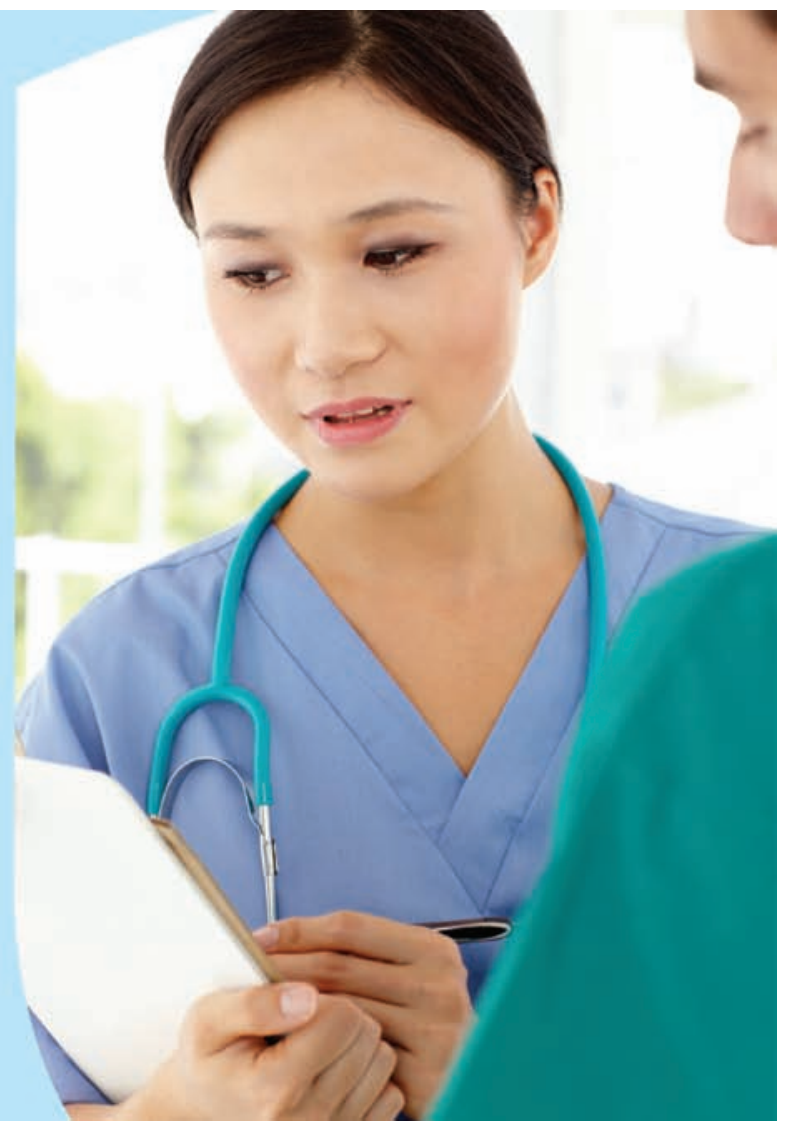

